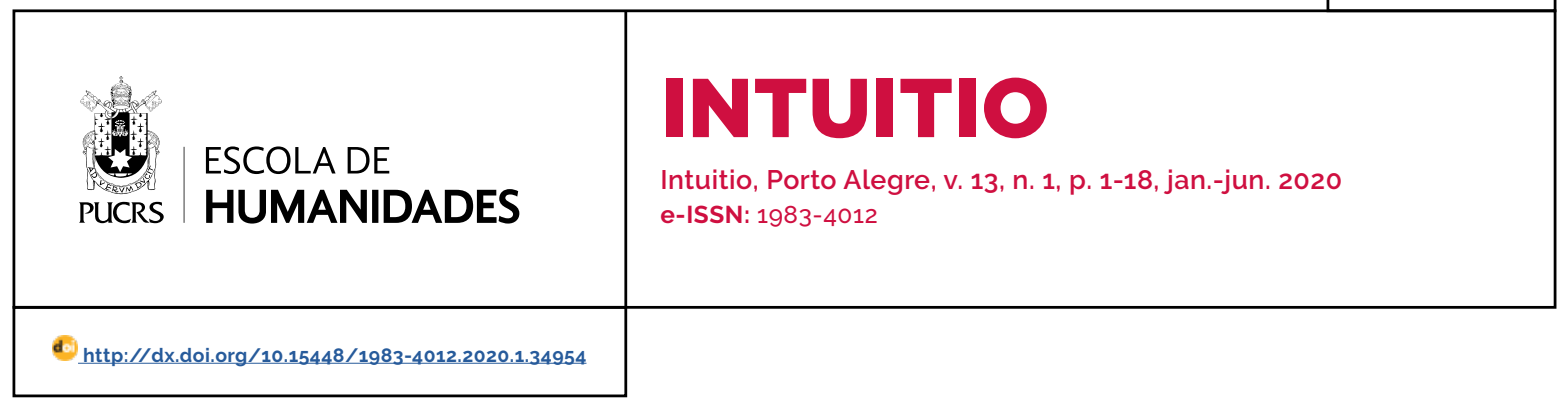

ARTIGO

\title{
Pós-modernidade e as duas faces de Janus: o Cogito Digital e - Solipsismo diante da desconstrução da metafísica
}

\author{
Post-modernity and the two faces of Janus: the Digital Cogito and the Solipsism in front \\ of the deconstruction of metaphysics
}

\section{Alessandra Cavalcante Scherma Schurig ${ }^{1}$} orcid.org/0000-0002-8268-6215 alessandra.schurig@ufba.br

Recebido em: 23 jul. 2019. Aprovado em: 21 ou.t 2019 Publicado em: 27 jul. 2020

\section{(c) (1)}

Artigo está licenciado sob forma de uma licença Creative Commons Atribuição 4.0 Internacional.
Resumo: O artigo analisou a ideia de pós-modernidade focando-se em dois problemas especificos da era digital, pós-verdade e a propagação de fake news, testando a hipótese de classificação desses problemas como resultados céticos da desconstrução filosófica levada adiante na pós-modernidade por teorias como a teoria pós-moderna deflacionista sobre a verdade formulada por Richard Rorty. Após a análise foi possivel concluir que a teoria deflacionista de Richard Rorty possui bases contextualistas e falibilistas opostas ao ceticismo e favoráveis à autorreflexividade e intersubjetividade que servem de recurso para a resolução dos problemas analisados que são classificados como adeptos do cogito digital de base metafísica.

Palavras-chaves: Pós-Verdade. Falibilismo. Contextualismo. Ceticismo. Solipsismo. Intersubjetividade.

Abstract: The article analyzed the idea of post modernity through two problems, post-truth and fake news, aiming test the hypothesis to classify this problems like skeptics results of a metaphysical deconstruction made in post-modernity by theories like the deflationary theory of truth formulated by Richard Rorty. After analyzing the deflationary theory, it's defended that the developing of a theory about truth fallibilist and contextualist like the theory of Richard Rorty promotes reflexivity and intersubjectivity that could be the resolution for the problems seen, classified like problems from digital cogito of a metaphysical source.

Keywords: Post-Truth. Fallibilism. Contextualism. Skepticism. Solipsism. Intersubjectivity.

\section{Introdução}

O presenteartigo pretendeverificar se existe correlação entre a desconstrução da metafísica e o rechaço dos dualismos fundacionistas realizados na pósmodernidade filosófica e problemas enfrentados na era digital tais como a pós-verdade e fake news. E, com isso, demonstrando que tais questões representam, na verdade, expurgos do domínio do paradigma metafísico.

Apresenta-se a hipótese de que problemas como a pós-verdade e a propagação de fake news são problemas sustentados em um paradigma metafísico, resumidos na ideia do cogito digital: o adepto da pós-verdade e o propagador de uma informação classificada como falsa são indivíduos que de tudo duvidam, exceto de si e de suas crenças, por ele classificadas como não ideológicas, neutras e aptas à captação da Verdade. 
A pesquisa ora realizada é eminentemente teórica e qualitativa. Utiliza o procedimento metodológico de análise de conteúdo bibliográfico e busca, diante da exposição dos argumentos e análises realizadas, apresentar a hipótese de que a pós-verdade e a propagação das fake news são problemas correlatos ao essencialismo e, portanto, contrários aos preceitos levados adiante pela filosofia abarcada pela teoria pós-moderna ou de modernidade tardia. Para isso, concentra a análise na teoria sobre a verdade e na crítica ironista, formulada por Richard Rorty, por meio da exposição de suas raizes hermenêuticas, contextualistas e falibilistas.

O objetivo é investigar qual paradigma filosófico sustenta a noção de pós-verdade e a disseminação de fake news. E, dessa forma, demonstrar que a rejeição da metafísica não tem correlações com tais problemas da era digital, sendo, de fato, antíteses deles. Para tanto, é preciso ter em vista que as teorias de Richard Rorty buscam, de fato, apresentar a noção de verdade intersubjetiva através do combate à metafísica, a primazia da autorreflexividade e da abertura ao Outro.

Para compreender como o paradigma metafísico pode sustentar os dois problemas especificos apontados, quais sejam, pós-verdade e fake news, é interessante retornar ao início da era digital, que começou com a promessa de democratização da informação e ampliação do conhecimento. É preciso entender que tais promessas se conectam a uma questão de base para a epistemologia, que gira em torno de duas questões fundamentais: o que é conhecimento e como podemos conhecer.

Sosa e Greco apontam que, por vezes, surge uma terceira questão: como conhecemos o que conhecemos? As respostas para essas perguntas serão as mais diversas possiveis. Por isso, buscando tecer uma definição ampliada sobre o que é conhecimento, Zagzebski ${ }^{3}$ fala sobre a possibilidade de definir o tema como um estado altamente valorizado no qual se encontra uma pessoa em contato cognitivo com a realidade.
Na definição formulada por Zagzebski, destacase a crença na existência de dois lados: de um lado estaria aquele que deseja conhecer, do outro lado estaria a realidade a ser conhecida. Ele ainda distingue dois tipos de conhecimento, definindo que há o conhecimento por familiaridade quando há contato direto com a experiência e há aquele proposicional, quando se faz uma proposição sobre o mundo.

Nesse sentido, um dos conceitos explorados pelas teorias de Richard Rorty, filósofo pósmodernista, é que todo conhecimento seria proposicional. Tal consideração é desenvolvida após a adoção do paradigma da linguagem, que derruba um dos dualismos que sustentava a metafísica e estava contido na definição ofertada por Zagzebski sobre essa existência de dois lados: o lado da realidade a ser conhecida e, do outro, aquele que deseja conhecer. É um dualismo típico do chamado essencialismo, porque pressupõe uma separação entre sujeito e objeto que leva à uma crença sobre a possibilidade de ponto neutro ou arquimediano, uma espécie de metanivel ao qual deveria alçarse aquele que deseja conhecer para realizar uma descrição exata e objetiva sobre a realidade.

Para Richard Rorty, a busca dessa descrição objetiva foi reforçada ao longo do tempo de domínio da metafísica, fortalecendo o paradigma da procura por objetividade que dominou a modernidade. Dialeticamente à modernidade, surgiu a pósmodernidade e, com ela, novos problemas.

Partindo da premissa de que a filosofia acomodou-se em um paradigma metafísico por tempo demais para se adaptar rapidamente aos tempos de incerteza, insegurança e brutal florescer de contingências que vicejam na pós-modernidade, quando as contingências sufocadas na modernidade ressurgem com força máxima, levam à dúvida sobre a possibilidade de objetividade e neutralidade. Entretanto, de forma característica, a dúvida sobre esses temas foi reforçada na era digital que enfrenta problemas como a pós-verdade e a propagação de fake news, e esse complemento levou não à 
continuidade da desconstrução da metafísica, mas a uma retomada da metafísica.

Ou seja, de início, acreditava-se que a era digital permitiria a ampliação e prosperidade nas trocas informacionais encaminhando para uma noção de verdade intersubjetiva e de abertura ao Outro. Todavia, o que ocorreu foi um encapsulamento e um solipsismo que são problemas típicos da metafísica e não da pós-modernidade.

Mesmo assim, teorias pós-modernas, tais como as formuladas por Richard Rorty, sofrem acusações de ceticismo e de veiculadoras de situações que levam ao caos informacional. Nesse sentido, frente à caracterização da pósmodernidade como época de fragmentação e questionamento de metarrelatos, desponta o questionamento se, de fato, teorias deflacionistas sobre a verdade como a de Rorty, contribuíram para o quadro que gerou problemas na troca de informações da era digital.

Para responder a esse questionamento, é interessante começar por compreender como éa subjetividade que alimenta os problemas da era digital e como ela está relacionada à metafísica subjetivista de Descartes e não a teorias pósmodernas como a formulada por Richard Rorty.

\section{Cogito Digital: A Subjetividade Como Pano De Fundo Para O Despontar Da Pós-Verdade E Das Fake News}

Bauman faz um importante alerta sobre o fato de que na pós-modernidade "a luta não é contra o senso comum, mas para eleger a única teoria das verdades". ${ }^{4}$ É uma constatação da relevância sobre a questão da verdade que se liga diretamente aos questionamentos da epistemologia e podem, portanto, ligar-se aos paradigmas filosóficos.

Nesse sentido, diante da avalanche informacional, quem detém o poder da verdade, ganha poder real na sociedade, seja econômico, político, social, i.e., resultados de um poder informacional. Enfim, deter o poder da verdade significa ter a autoridade para determinar quais informações podem receber o status de verdade ou não. No mundo pós-moderno, com uma ampla liberdade de dados, saber que elementos recebidos devem ser tratados como confiáveis e verdadeiros - e, por isso, merecer relevância - é tema que ganha cada vez mais importância.

Na modernidade, questões como essa eram regidas por uma preocupação com a segurança e o clamor principal era por liberdade, clamor que acaba sendo reconhecido na pós-modernidade, onde se tem liberdade, inclusive de informação. Entretanto, será diante dessa liberdade informacional que desponta um quadro composto por subjetividade como guia para avaliação dos dados. Isso porque, perante a internet, o individuo parte, de fato, de uma base cartesiana, formulando um cogito diante do que deve ser avaliado.

Perceba-se que Heidegger chama atenção que "o cogito (...) reflete o padrão por excelência da matemática aplicada à filosofia, ou seja, da cientifização, da necessidade de aplicação dos métodos das ciências naturais". ${ }^{5}$ Descartes adota as ideias de Platão e inicia a filosofia moderna, e a metafísica objetivista torna-se então metafísica subjetivista em suas mãos, porque ele retrata a ideia do sujeito transcendental e transcendentaliza o "eu". Penso, logo existo ou penso, portanto sou, eis o cogito, a máxima cartesiana que parte da indubitabilidade do eu.

Foi Descartes quem liberou a filosofia da teologia, conta-nos Heidegger, que revela ainda que a filosofia cartesiana começou pela dúvida. Foi, justamente, quando Descartes começou a duvidar de tudo até declarar que quem duvida não pode duvidar de sua própria existência.

Note-se que com Platão havia uma essência em todas as coisas. Agora, com Descartes, há a ideia de um "eu" que subjaz aos objetos, porque ele toma o pensar como um colocar para si mesmo o que é representável e o pensar coloca para si esse "eu" que está em todas as representações. Descartes, portanto, modifica o pensamento platônico que valorizava as coisas por si mesmas.

No cartesianismo, as coisas têm "uma relação 
fundante com o "eu" dotado da razão". Enfim, com Descartes a noção de "eu" tornou-se transcendental, na medida que seria esse "eu" quem determinaria as coisas que o circundam. Até então, as coisas tinham valor por si mesmas; a partir dele, as coisas passaram a manter uma relação fundamental e transcendental com o homem, pois é o homem que daria às coisas sua coisalidade.

Ressalte-se a questão da indubitabilidade para Descartes: quem duvida não pode duvidar de sua própria existência e assim, o que se torna fora de qualquer dúvida, será o "eu". Heidegger, ao discorrer sobre Descartes, explica que dotado da razão estaria o "eu" que pensa; pois "penso, logo existo... na medida em que duvido, devo ao mesmo tempo admitir que "sou", o "eu" é, portanto, aquilo que é indubitável".7 Compreendido o cogito, há que se pensar no cogito digital e em como esse a metafísica subjetivista foi transportada para o usuário das redes. Esse usuário de tudo duvida, exceto de si mesmo, mas duvida da mídia tradicional, duvida das instituições oficiais, duvida de doutrinadores, pesquisadores, professores. Duvida de todo aquele que se debruçou e pesquisou sobre um tema, possivelmente por longos anos, mas não duvida de si mesmo.

O seu Eu, suas crenças, são tomadas como indubitáveis e são reafirmadas por seu grupo e, assim, ganham mais força. Não se busca o Outro, se busca a si mesmo. Tem-se a ilusão de ampla liberdade, mas de fato, a estrada seguida é a estrada do Eu.

A partir dessa premissa, pode-se inferir que há uma grande solidão envolvida na, supostamente ampla, troca informacional. Apesar da amplitude da rede, a busca não é por intersubjetividade e sim por subjetividade que se emaranha ao ceticismo em uma complexa teia.
E será dessa teia que surgirá um conceito típico da pós-modernidade, representativo dos dilemas informacionais da era contemporânea, a chamada "pós-verdade, um termo já incorporado ao vocabulário da mídia mundial, (...) parte de um processo inédito provocado essencialmente pela avalancha de informações gerada pelas novas tecnologias de informação e comunicação (TICS)".

Pós-verdade é a palavra definida pelo dicionário de Oxford ${ }^{9}$ como um adjetivo que denota uma situação na qual fatos objetivos têm influência menor na modulação da opinião pública do que apelos para a emoção e crenças pessoais. $^{10}$ É o primado da subjetividade na avaliação da informação que resulta em caos na questão da busca por conhecimento confiável em um mundo intensamente dualizado e com dificuldades práticas na lida diária com a questão da informação e da verdade.

A situação alcança um ápice nunca visto diante do advento das redes sociais, "estruturas dinâmicas e complexas formadas por pessoas com valores e/ou objetivos em comum, interligadas de forma horizontal e predominantemente descentralizada"11 Perceba-se que essa horizontalidade estava no cerne de uma das promessas da internet: a restituição à comunidade da importante possibilidade de emissão da informação e conhecimento. Considerava-se que com a quebra da verticalização da informação "haveria a expansão do saber e da participação política do cidadão comum nas democracias liberais de hoje".12

Em suma, acreditava-se que a chamada democracia digital expandiria a possibilidade de participação da sociedade na política e isso fortaleceria a democracia deliberativa e a troca comunicacional, fortalecendo a intersubjetividade. A sociedade percebeu, primeiro de modo

\footnotetext{
HEIDEGGER, M. O que é uma coisa? 1987, Lisboa, Edições 70, p. 108

HEIDEGGER, M. O que é uma coisa? Lisboa: Edições 70, 1987. p.102.

CASTILHO, C. Apertem os cintos: estamos entrando na era da pós-verdade. Observatório da Imprensa, 2016.

"POST-TRUTH" In: On-line Oxford Dictionary of English. Disponivel em https://www.lexico.com/en/definition/post-truth. Acesso em 15 jul. 2019.

10 CABETTE, A., F. "O que é 'pós-verdade', a palavra do ano segundo a Universidade de Oxford" In: Nexo Jornal, edição de 16 de novembro de 2016. Disponivel em: https://www.nexojornal.com.br/expresso/2016/11/16/O-que-\%C3\%A9-\%E2\%80\%98p\%C3\%B3s-verdade\%E2\%80\%99-a-palavra-do-ano-segundo-a-Universidade-de-Oxford. Acesso em: 12 mar. 2019.

11 SOUZA, Q. R.; QUANDT, C. O. "Metodologia de Análise de Redes Sociais" In: DUARTE, F.; QUANDT, C. O.; SOUZA, Q. (orgs.). O Tempo das Redes. São Paulo: Perspectiva, 2008, p. 34.

12 GOMES, W. "A democracia digital e o problema da participação civil na decisão política" In: Revista Fronteiras: estudos midiáticos, v.7. n.3. pp.214-222, 2005. Disponivel em http://revistas.unisinos.br/index.php/fronteiras/index. Acesso em: 27 jan. 2020. p. 216.
} 
exuberante e afoito, que uma nova era chegava por meio das redes sociais e festejou o fato de os grandes conglomerados de mídia não serem mais os únicos detentores da informação.

Nessa época, ainda se presumia que a informação seria democratizada e capilarizada e um mundo em que todos seriam esclarecidos e participativos estava por surgir. A internet nascia para combater a verticalização das mídias tradicionais, composta pelo dualismo de produtores e receptores, presos a uma única versão. Havia o desejo de proteção de liberdades individuais e, finalmente, da restituição à comunidade da possibilidade de emissão da informação.

Esse era questão satélite das reflexões sobre problemas da democracia representativa, da política profissional e do afastamento da sociedade civil do cenário político. Além disso, considerava-se que seria papel da internet resolvero problema da participação do público na politica que afeta as democracias representativas liberais contemporâneas, tornaria esta participação mais fácil, mais ágil e mais conveniente (confortável, também). ${ }^{13}$

Entretanto, esse novo meio de propagação de conhecimento, sem intermediários, acabou por gerar problemas severos e ainda sem solução. Um deles é trazido por Hunt Allcott e Matthew Gentzkow que, em 2017, realizaram estudo amplo sobre redes sociais e fake News.

Eles alertaram que as redes sociais consubstanciam uma mudança tecnológica jamais vista nas mídias anteriores. Os autores destacam que nas mídias sociais o conteúdo pode ser distribuido entre usuários sem que haja uma terceira parte intermediando, filtrando, checando os fatos ou um julgamento editorial. ${ }^{14}$ Esse assunto, que era celebrado na época de ouro da internet como a democratização da informação, revelou-se um perigo, de fato, haja vista que criou o ambiente propício para a proliferação das chamadas fake news.

Eles definem fake news como "artigos e notícias que são intencional e verificadamente falsos tendo potencial para enganar leitores." ${ }^{15}$ Ressalte-se esse ponto: são notícias deturpadas deliberadamente em razão de um objetivo camuflado, o que novamente recorda a tese proposta por Bauman, quem detém o estandarte da verdade, detém o poder.

Allcott e Gentzkow definem um método de análise das fake news e explicam que elas podem ser analisadas sob diversos vieses. Partindo dos fatores conjunturais apontados, é possivel eleger ao menos cinco principais elementos para a proliferação de fake news: baixo custo de produção, forma de compartilhamento, segregação ideológica, desconfiança nas midias tradicionais e motivação camuflada dos produtores.

Considerando com brevidade os fatores apontados, o baixo custo de produção relacionase a uma análise do ponto de vista econômico. Fake news são consideradas sinais distorcidos, não relacionados com averdade, propagadas velozmente porque custam menos para serem produzidas. Isso porque não há checagem, editoração, cotejamento com informações, envio de jornalistas aos locais dos acontecimentos, não há nada similar a tais precauções, apenas a simples produção e envio do que foi produzido para as mídias sociais.

Além disso, Allcott e Gentzkow apontam que consumidores não podem aferir a veracidade das noticias recebidas pelas mídias sociais sem custos. Nesse sentido, é interessante observar que os planos de operadoras de internet no Brasil, em regra, disponibilizam redes sociais de modo gratuito, enquanto o uso para navegadores é cobrado, conforme explicam matérias divulgadas em sites jornalísticos e o próprio material de divulgação das empresas.

Desse modo, cabe a reflexão sobre o fato de que seria o acesso a navegadores que

\footnotetext{
13 GOMES, W. A democracia digital e o problema da participação civil na decisão política. In: Revista Fronteiras: estudos midiáticos, v.7 n.3. p.214-222, 2005. Disponivel em http://revistas.unisinos.br/index.php/fronteiras/index. Acesso em: 27 jan. 2020. p. 218.

14 ALLCOTT, H.; GENTZKOW M. Social Media and Fake News in the 2016 election. In: Journal of Economic Perspectives, v.31, n.2, 2017, pp. 211-236. Disponivel em: https://www.aeaweb.org/articles?id=10.1257/jep.31.2.211. Acesso em: 27 jan. 2020. p.211, tradução nossa.

15 ALLCOTT, H.; GENTZKOW M. Social Media and Fake News in the 2016 election. In: Journal of Economic Perspectives, v. 31, n. 2, 2017, p. 211-236. Disponivel em: https://www.aeaweb.org/articles?id=10.1257/jep.31.2.211. Acesso em: 27 jan. 2020. p.211, tradução nossa.
} 
possibilitaria a checagem da informação recebida por mídias sociais e, quiçá, essa atitude de checagem seria hábil para a interrupção de propagação de notícias deturpadas.

Outro ponto apontado por Allcott e Gentzkow é que fake news podem - e esse é um aspecto a ser destacado - gerar utilidade para alguns consumidores interessados em propagar determinada informação. Estes podem visar algum beneficio, em especial, pecuniário; já que, quando os artigos se tornam virais, há monetização para cada clique de usuários no site original.

Mas há, também, e não menos significativa, a motivação ideológica ${ }^{16}$ Entretanto, os autores alertam que, ao mesmo tempo em que geram utilidade, "fake news impõem custos privados e sociais."17

Como exemplos desses problemas, citam que consumidores que são induzidos a acreditar em crenças com grau baixo de precisão e legitimidade serão menos informados. Além disso, tais convicções reduzem externalidades positivas como a habilidade de seleção de candidatos em um processo democrático. Em terceiro, os autores apontam que os consumidores de fake news tornam-se mais e mais céticos sobre legitimar novos produtores de informação. E, por fim, esses efeitos são reforçados por uma demanda reduzida por dados precisos e exatos - o que leva a uma redução na produção de tais informações. O ganho antevisto pelos autores resume-se ao bemestar dos leitores desses relatos que gostam de ler e comentar notícias falsas que são correlatas à sua maneira de ver o mundo. ${ }^{18}$

Destarte, justamente por deturparem processos de informação e conhecimento, há uma série de problemas graves que são resultados da propagação de fake news. Por isso, ainda é necessário considerar que os problemas citados tendem a piorar com a desconfiança cada vez maior na mídia tradicional.
Isso pode ser ao mesmo tempo causa e consequência da popularização das fake news. Ainda é preciso recordar, como fazem os citados autores, que somado ao custo baixo de produção, há o próprio formato das redes sociais, já que geralmente tanto o propagador como o receptor não leem em sua totalidade o artigo ou notícia e. sim, apenas alguns pedaços de informação. Dessa forma, isso dificulta ainda mais o julgamento sobre a veracidade do que é narrado.

É ainda sobrelevado por Allcott e Gentzkow um ponto que vem sendo estudado há algum tempo e apontado por especialistas como um problema grave que, em algum momento, causaria uma ruptura comunicacional: a segregação ideológica promovida e alimentada pelas redes sociais. É aqui, nessa separação, que se encontra a face mais óbvia do cogito digital, da subjetividade e da busca do Eu através da recusa do Outro.

Nesse sentido, como o compartilhamento de informações é feito em regra entre pessoas que detém ideologia semelhante e, por isso, são formados grupos coesos que compartilham os mesmos temas, sob o mesmo viés ideológico. Nessa linha, a prestigiada revista Science publicou em 2015 um artigo que mostrava a existência do que recebeu o nome de bolha ideológica. Nele mostrava que o Facebook serve como uma espécie de caixa de ressonância para uma ideia que não sendo confrontada com outras diversas, passa a ter valor de verdade. ${ }^{19}$ Isso demonstra novamente o papel da subjetividade na nova era informacional.

Analisando especificamente a situação brasileira, o estudo publicado em maio de 2018, na Friedrich Ebert Stiftung, por Esther Solano, percebe uma questão relevante. Um dos fatores estruturais apontados pela pesquisadora como causais para a crise na democracia no Brasil seria o paradoxo entre os tempos sociais (intensos e acelerados tecnologicamente) e o tempo político (representativo,

\footnotetext{
16 ALLCOTT, H.; GENTZKOW M. Social Media and Fake News in the 2016 election. In: Journal of Economic Perspectives, v.31, n.2, 2017, pp.211-236. Disponivel em: https://www.aeaweb.org/articles?id=10.1257/jep.31.2.211. Acesso em: 27 jan. 2020, p. 217, tradução nossa.

17 ALLCOTT, H.; GENTZKOW M. Social Media and Fake News in the 2016 election. In: Journal of Economic Perspectives, v.31, n.2, 2017, pp.211-236. Disponivel em: https://www.aeaweb.org/articles?id=10.1257/jep.31.2.211. Acesso em: 27 jan. 2020, p. 212, tradução nossa.

18 ALLCOTT, H.; GENTZKOW M. Social Media and Fake News in the 2016 election. In: Journal of Economic Perspectives, v.31, n.2, 2017, p. 211-236. Disponivel em: https://www.aeaweb.org/articles?id=10.1257/jep.31.2.211. Acesso em: 27 jan. 2020, p. 219, tradução nossa.

19 ADAMIC, E. BAKSHY S. MESSING L. Exposure to ideologically diverse news and opinion on Facebook. In: Science, 05 jun. 2015 , v.348, n.6239, p. 1130-1132. Disponivel em: https://science.sciencemag.org/content/348/6239/1130. Acesso em: 27 jan. 2020
} 
vagaroso e que não saberia lidar com a substituição do espaço público de debate pelo protagonismo dos meios de comunicação de massa). ${ }^{20}$

É assim que o papel das redes sociais no espectro político brasileiro é abordado, pois o afastamento dos partidos e a hiperconectividade seriam problemas relevantes, segundo aponta a pesquisadora, para quem:

as formas de organização online e seu impacto radical na democracia, até com efeitos não esperados e muito desconcertantes como o fenômeno das fake news ou boatos virtuais ou a utilização de Big Data em campanhas eleitorais, para influenciar as preferências políticas do eleitor. ${ }^{21}$

Destarte, na pós-modernidade, surgem as redes sociais e seu devastador poder de propagação de pós verdade e fake news, conceitos entrelaçados. E diante do problema de saber como administrar a confiabilidade das informações, surgem as supostas conexões entre pós-verdade, fake news e a desconstrução da metafísica levada adiante pela pós-modernidade, em especial por Richard Rorty.

\section{Dialética Modernidade/Pós-Modernidade e o Dilema Entre Liberdade e Segurança na Face Escura da Pós-Modernidade}

A pós-modernidade deve ser compreendida em oposição à modernidade, como a época de revolta contra a objetividade e as promessas da modernidade. Partir dessa premissa é partir de uma posição que defende uma espécie de dialética entre paradigmas filosóficos. Se na modernidade o que se buscava era a segurança e a objetividade, na pós-modernidade há que se lidar com a liberdade.

Para Bauman, ${ }^{22}$ a pós-modernidade é a época na qual fica cada vez mais claro que, quando se ganha alguma coisa, se perde algo em troca. E essa é uma reflexão poderosa, pois a modernidade defendia a abdicação de parcelas de liberdade visando ganhar em objetividade, civilização e ordem. Mas, na pós-modernidade, o que se busca? O que se ganha? O que se perde?

Nesse sentido, é possivel responder que o principal ganho da pós-modernidade ocorreu em termos de liberdade, incluindo a autonomia na questão da busca do conhecimento. Bauman esclarece que liberdade "é o nosso destino, uma sorte de que não se pode desejar o afastamento e que não se vai embora por mais intensamente que possamos desviar dela os nossos olhos".23

Essa emancipação veio como resultado de fatores como a desconstrução do pensamento sobre a objetividade e, também, da situação factual de um mundo com múltiplas identidadese narrativas diversas que celebravam a diversidade de ideias, a variedade e a diferença. Como explica Teubner, ${ }^{24}$ um mundo onde viceja a policontexturalidade de sentidos, em uma época que duvida de procedimentos kantianos, da ideia de razão e que leva ao surgimento de estruturas sociais intermediárias e altamente fragmentadas.

Essas estruturas fragmentadas que se alastram na pós-modernidade são o resultado do que Lyotard chamou de falência das metanarrativas. O autor explica que o pós-moderno, enquanto condição de cultura nesta era, caracterizase exatamente pela "incredulidade perante o metadiscurso filosófico-metafísico, com suas pretensões atemporais e universalizantes". 25

Desta feita, após tais concepções, é possivel chegar a outra conclusão, uma que nos diz que o pós-moderno representa também esse combate da metafísica que acabou por proporcionar ganhos no quesito liberdade por meio do entendimento de que existem diversos pontos de vistas, relatos e narrativas a serem consideradas. Essa é a face, por assim dizer, sadia da pós-modernidade.

Contudo, tal qual Janus, o deus romano

\footnotetext{
20 SOLANO, E. Crise da democracia e extremismos de direita. In: Friedrich-Ebert-Stiftung Brasil, n.42, maio de 2018. Disponivel em: http:// library.fes.de/pdf-files/bueros/brasilien/14508.pdf. Acesso em: 27 jan. 2020, p. 06.

${ }_{21}$ SOLANO, E. Crise da democracia e extremismos de direita. In: Friedrich-Ebert-Stiftung Brasil, n.42, maio de 2018. Disponivel em: http:// library.fes.de/pdf-files/bueros/brasilien/14508.pdf. Acesso em: 27 jan. 2020, p. 06.

22 BAUMAN, Z. O mal-estar na pós-modernidade. Rio de Janeiro: Zahar, 1997, p. 7.

23 BAUMAN, Z. O mal-estar na pós-modernidade. Rio de Janeiro: Zahar, 1997, p. 251

24 TEUBNER, G. Direito, sistema e policontexturalidade. Piracicaba: UNIMEP, 2005, p. 20

25 LYOTARD, J.F. A condição pós-moderna. Rio de Janeiro: José Olympio, 2009, p. IX
} 
das transições, o novo paradigma filosófico da pós-modernidade tem duas faces. Se a compreensão da multiplicidade de narrativas é a parte iluminada, esclarecida e limpida, a face obscurecida passa por entender que o que foi perdido, quiçá para sempre, foi a sensação de segurança proporcionada pelo berço metafísico, em especial em relação ao conhecimento antes classificado como verdadeiro, posto que o próprio conceito de Verdade passou a ser questionado.

Para entender essa questão, é preciso recordar que, até a pós-modernidade filosófica, usualmente discutir temas sobre conhecimento e verdade eram questões sob o dominio de três grandes teorias substancialistas: teoria correspondentista, teoria coerentista e teoria pragmática.

A teoria correspondentista é também denominada como teoria sobre a verdade como correspondência. Ela trabalha com a correspondência entre uma asserção linguistica e um estado de coisas no mundo.

A segunda teoria é a teoria da verdade como coerência. Ela define verdade como uma qualidade que pode ser aplicada a relações mutuamente convergentes entre um conjunto de asserções linguísticas. Assim, é vista como uma qualidade interna e serájulgada em relação às outras sentenças concernentes a um campo de conhecimento. ${ }^{26}$

E, por fim, há a teoria da verdade pragmática. Essa teoria abrange uma infinidade de posicionamentos, rejeitando tanto a da verdade como correspondência como a da verdade como coerência. Para a teoria da verdade pragmática, o foco é o auditório e os efeitos das crenças e por isso exsurge a ideia da verdade como consenso, enfatizando a argumentação, o diálogo e vendo verdade como assertabilidade garantida. ${ }^{27}$

Será diante desse domínio de teorias substancialistas sobre a verdade que, após a virada linguística, surgem as ideias desenvolvidas por Richard Rorty. Ele cria uma peculiar teoria sobre a verdade, inserida no contexto das teorias deflacionistas sobre o assunto que fazem parte do paradigma filosófico pós-moderno.
Rorty destaca a importância da teoria da verdade pragmática, mas explica que detinha um cunho realista que só posteriormente à adoção do paradigma da linguagem pela filosofia não analítica realizou a passagem para o neopragmatismo, abandonando o realismo em favor da linguagem. É sobre essas transições que ele trabalha.

O foco da teoria deflacionista sobre a verdade desenvolvida por Richard Rorty na pós-modernidade será combater o paradigma metafísico e para isso sustenta a ideia de verdades, com letras minúsculas e no plural, em oposição à Verdade singular e com letra maiúscula do essencialismo. Para ele, a maior busca pós-moderna é pela intersubjetividade e a metafisica é um obstáculo a essa visão.

Uma das principais ideias combatidas pelo autor será a ideia do suposto contato direto com a realidade como fonte de conhecimento. Rorty desenvolve uma teoria que defende que todo conhecimento é proposicional e que os limites da nossa linguagem são os limites do nosso mundo.

Para ele, crenças, teorias e linguagem não devem servistos como defesas contra a concretude dos dados, contra a objetividade e muito menos devem ser vistos como véus que se interpõem entre o homem e a realidade que o circunda, mas como meios inarredáveis do próprio olhar humano. Fazendo jus à tradição hermenêutica, ressalta que o homem não pode se afastar de sua tradição e de seu contexto, pois o homem só compreende por conta dessa tradição e desse contexto que podem até passar por um filtro reflexivo, mas isso não servirá nunca como garantia de imparcialidade e objetividade, contudo, tal filtro pode encaminhar para a compreensão do Outro.

As ideias expostas por Richard Rorty fazem parte de um amplo espectro pós-modernista que realizou questionamentos reiterados sobre a defesa da objetividade e da imparcialidade, desejando derrubar a visão metafísica sobre a verdade e o conhecimento. Justamente por isso, os críticos de teorias pós-modernas afirmam que foram também esses questionamentos 
os responsáveis pelo o que Bauman chama de "incessante processo de incertização"28 do mundo; ou seja, que as ideias pós-modernas possuiriam a face escura, de perda da segurança, como única contribuição e relevo.

O processo de incertização seria então consequência da pós-modernidade, um dos resultados da perda de segurança que atingiu o cerne da questão sobre conhecimento, nutrindo dúvidas sobre como definir conhecimento verdadeiro, sobre como definir o que é verdade. É neste momento que viceja uma imensa multiplicidade de relatos, unido à dificuldade na construção de consensos. É diante desse quadro que, acredita-se, teria sido justamente a falência das metanarrativas e a descrença na metafísica, fatores responsáveis por um intenso debater sobre contingências, as causas que levaram a um forte apelo pela Verdade e a um penoso debate sobre como alcançá-la.

É o que assevera Pascal Engel quando, em um interessante debate sobre a verdade com Richard Rorty, o acusa de acabar por alimentar o terror e a censura em razão de seu antirracionalismo. Engel, filósofo da linguagem, pragmatista teórico, afirma que, mesmo apesar da desconfiança contra os valores da racionalidade e do progresso científico, a impressão de ser enganado pelos poderes faz com que cresça cada vez mais a necessidade de confiança e estabilidade e, por isso, teorias que dizem que verdade e racionalidade são palavras vazias são teorias incoerentes ou cínicas. Para ele, é evidente que as pessoas precisam reter algum conceito de verdadeiro e de verdade, porque a sede de veracidade está sempre pairando e presente, como uma espécie de substituto de certezas antigas que eram dadas, por exemplo, pela religião. ${ }^{29}$

Pascal Engel chama os pós-modernistas de verifobos: aqueles que creem que verdade é uma palavra vazia. Além disso, afiança que Richard Rorty é um típico exemplar de um relativista pós- modernista ${ }^{30}$ que, ao desconstruir a metafísica, desenvolveu uma absurda teoria deflacionista sobre a verdade. Portanto, Engel acredita que teria sido através do desenvolvimento e expansão de teorias pós-modernistas, como as formuladas por Richard Rorty e outros filósofos pós-modernos, que conceitos como objetividade e verdade foram corroidos negativamente.

É a mesma censura formulada por Ronald Dworkin que, ao tratar acerca da objetividade e verdade, critica firmemente as teorias de Rorty e seus conceitos sobre verdade, o acusando de ceticismo. Ao tratar sobre ceticismo, Dworkin cinde o conceito em ceticismo externo ou arquimediano e ceticismo interno.

Assim, ao discorrer sobre o tema, Dworkin afirma acreditar que o ceticismo externo é uma tese que ganhou nomes diversos como pós-modernismo, antifundacionalismo e neopragmatismo. Todos são exemplos de ceticismo externo que, para ele, apoia-se em duas premissas: neutralidade e austeridade. ${ }^{31}$ Para o autor, essa é uma forma muito atraente para a sociedade atual e cita que Richard Rorty chama esse estado mental de ser ironista.

Dworkin explica que o ceticismo externo ou ceticismo arquimediano ganhou nomes diversos como pós-modernismo, antifundacionalismo e neopragmatismo, todos exemplos de ceticismo externo que, para ele, se apoia em duas premissas: neutralidade e austeridade. O ceticismo externo ou arquimediano é definido por Dworkin como uma teoria metafísica, e não uma posição interpretativa ou moral. "O cético exterior não contesta nenhuma afirmação moral ou interpretativa específica"32, porque parte de um ponto de vista chamado arquimediano, do qual fará sua avaliação, classificada como neutra e austera.

Para ele, o ceticismo arquimediano reivindica neutralidade sobre opiniões substantivas acerca da moral e reivindica austeridade na defesa de argumentos morais, afirmando que a ideia de

\footnotetext{
BAUMAN, Z. O mal-estar na pós-modernidade. Rio de Janeiro, Zahar, 1997. p. 251.

ENGEL, P.; RORTY R. Para que serve a verdade? São Paulo:Unesp, 2007, p. 12.

ENGEL, P., RORTY R. Para que serve a verdade? São Paulo: Unesp, 2007, p. 16.

DWORKIN, R. Objectivity and Truth: You'd better believe it. In: Philosophy \& Public Affairs, v.25, n.2, 1996, p. 87-139. Disponivel em: https://www.jstor.org/stable/2961920. Acesso em: 27 jan. 2020, p. 113

32 DWORKIN, R. Objectivity and Truth: You'd better believe it. In: Philosophy \& Public Affairs, v.25, n.2, 1996, p. 87-139. Disponivel em: https://www.jstor.org/stable/2961920. Acesso em: 27 jan. 2020, p. 98
} 
objetividade sobre crenças morais não é possível e que seria arrogante dizer que determinado ponto de vista é objetivamente melhor. $\mathrm{Na}$ mesma linha, conforme visto, há para Dworkin o ceticismo interno, definido como acreditar que a verdade depende de valorações morais e questionar esse ponto, essas predicações, negando certos predicados morais positivos ou negativos para endossar uma perspectiva moral distinta. Amplamente, portanto, segundo o autor, o ceticismo seria sinônimo de pós-modernismo que por sua vez é sinônimo de neopragmatismo e que tem por seu maior expoente Richard Rorty e sua teoria deflacionista sobre a verdade, pois para Dworkin, Rorty é o mais "proeminente defensor do ceticismo arquimediano".33

Portanto, o ceticismo pode ser definido como uma opinião de segunda ordem sobre a impossibilidade absoluta de alcançar a verdade, somado à defesa de perspectivas morais subjetivas e dispares. Tendo sido examinadas as questões que levam à formação da pósverdade, quando fatos são ignorados em favor de considerações pessoais e da disseminação de fake news como uma das formas de manipulação da informação, pode-se concluir que há uma conexão firme entre esses temas e o ceticismo, tanto em sua visão externa, como interna.

Definida essa conexão, cabe observar se há fundamentos nas críticas formuladas por Engel e Dworkin. E, assim verificar se as teorias desenvolvidas por Richard Rorty, ao desconstruir a metafísica e questionar a possibilidade de objetividade, representam de fato teorias céticas.

\section{A Outra Face de Janus na Face de Esperança da Pós-Modernidade: 0 Contextualismo e o Falibilismo das Teorias de Richard Rorty}

O que se percebeu até aqui foi que a pósmodernidade se erigiu dialeticamente em oposição à modernidade, buscando a liberdade. E, com isso, Richard Rorty, filosofo pós-moderno, debateu e rejeitou as teorias substancialistas sobre a verdade, buscando um novo ponto de vista. Suas ideias sofreram desde o começo grande rejeição e ele foi chamado de cético.

Sendo o ceticismo um grande problema na época contemporânea chega-se ao ponto de analisar quais são as ideias do autor e se elas de fato fazem parte do ceticismo filosófico e somente contribuíram para o processo de incertização do mundo. Isso porque é comprovada a impactante relevância da sua teses quando são tratadas questões como fake news e pós-verdade.

Nesse ponto, cabe observar que uma das grandes resistências à teoria deflacionista de Richard Rorty vem do receio do abandono da metafísica, do medo que isso leve à sociedade a um caos que teria como reflexo, justamente, questões como pós-verdade, fake news, propagação de teorias conspiratórias e situações correlatas. Pois, se abandonada a Verdade e a objetividade, como se avaliaria a confiabilidade das informações?

Para responder a essa pergunta é preciso compreender que não há caminho de volta. A objetividade e a certeza, a segurança e a solidez da modernidade não voltarão, conforme explica Bauman. Para ele, a condição pós-moderna de incerteza não deve mais ser vista como um inconveniente temporário que "com o devido esforço possa ser ou abrandado ou inteiramente transposto". ${ }^{34}$ De fato, o autor afirma que o mundo pós-moderno está se preparando para a vida sob uma condição de incerteza permanente e irredutivel.

Associando-se a essa premissa de Bauman (para quem essa condição agora permanente de incerteza não pode ser superada e deve-se à nova desordem do mundo, onde não há mais qualquer estrutura lógica visivel na geopolítica), há excesso de desregulamentação em relação ao mercado que promove a volatilidade econômica, o esfacelamento das redes de segurança como grupos comunitários, vizinhança, famílias, etc. Enfim, há uma conjuntura de insegurança que fomenta o modo de ser do mundo contemporâneo,

\footnotetext{
33 DWORKIN, R. Objectivity and Truth: You'd better believe it. In: Philosophy \& Public Affairs, v.25, n.2, 1996, p. 87-139. Disponivel em: https://www.jstor.org/stable/2961920. Acesso em: 27 jan. 2020, p. 95.

34 BAUMAN, Z. O mal-estar na pós-modernidade. Rio de Janeiro: Zahar, 1997, p. 32.
} 
onde tudo pode acontecer, as contingências se avolumam e há uma mensagem geral de indeterminação. Entende-se que essa incerteza não pode ser superada e, por isso, é preciso questionar como combater problemas como a pós-verdade e a disseminação de fake news.

A resposta decorre não do resgate da metafísica, dos seus metarrelatos e de qualquer possibilidade de crença em essencialismo e segurança. De fato, ao se analisar os problemas que maculam as trocas informacionais, chegouse à conclusão do uso do cogito digital, esse solipsismo que abarca o usuário das redes sociais e o fazem alvo e propagador de informações falsas. Ao duvidar de tudo, menos de suas próprias impressões e das impressões de seu grupo, daqueles que enxerga como iguais, o usuário se utiliza de instrumentos metafisicos e nega a pós-modernidade.

É por isso que qualquer solução virá do seguir na desconstrução da metafísica, do modo que é realizado por Richard Rorty, que convoca ao abandono da concepção metafísica em favor de um modo não substancialista ou deflacionista de se lidar com a verdade. Dessa forma, desenvolve a teoria da verdade como redundância, diante da qual a questão sobre a verdade deve ser observada em razão da utilidade do predicado verdade, rejeitando qualquer possibilidade de diferenciação ontológica. O que ele busca é, justamente, acostumar-se à incerteza, à contingência, e não as rejeitar; e, assim, caminhar em direção à intersubjetividade.

Considerando o abandono do dualismo essência/aparência e a visão do conhecimento como proposicional, arguindo contra a visão do conhecimento "direto da realidade", Rorty sobreleva a questão do conhecimento proposicional e parte de origens pragmáticas em direção à adoção da teoria da filosofia não analítica da linguagem. Para isso, explica que toda palavra tem um sentido apenas se o falante dá um sentido para a palavra. E dar um sentido é algo que será feito mediante a utilização da palavra.

Diante disso, Rorty diz que o que importa é se o uso dessa palavra faz diferença na prática., ${ }^{35}$ Por isso não existe qualquer diferença ontológica entre 'verdade' e outras palavras, como 'gato' ou 'carpete', é apenas um constructo linguistico. Com o combate à metafísica, Richard Rorty passa a entender-se como um ironista ou quietista da linguagem e diz que não há nenhuma palavra que seja vazia de sentido e que todas as palavras têm o mesmo status ontológico, incluindo a própria palavra verdade. ${ }^{36}$

Bauman explica que James, um dos fundadores do pragmatismo, em 1912, já dizia que o verdadeiro é somente um expediente na nossa maneira de pensar ${ }^{37}$ Rorty explicou que esse expediente seria o uso elogioso, ou endossador, de certas crenças visando indicar uma atitude que se considera correta, elogiável e que se espera que outros adotem e não uma relação de correspondência com a realidade. Ele acrescenta à ideia de James sobre a verdade a ideia do uso descitacional e a função admonitória: uma função de alertar, como a da palavra perigo.

Será sobre esse paradigma deflacionista acerca da verdade que Richard Rorty desenvolve sua critica ironista. Para isso, ele define como uma verdadeira recusa de qualquer diferença na linguagem, esse "tecido sem costura", contribuindo para a "dissolução das distinções, já que estas opõem as qualidades primárias às qualidades secundárias, os fatos aos valores, a descrição à expressão, etc. Isso geraria uma linguagem plana e indiferenciada, que poderia conduzir ao ironismo, quietismo ou deflacionismo".38

É com base nessas premissas que Rorty assevera: não há nada metafísico, nem substancial na ideia de verdade. Quando se fala sobre isso, o que há é um costume reiterado e recomendado por certa sociedade em certo espaço de tempo, costume que pode se estender por várias épocas e muitos locais, costumes contextuais e que podem ser modificados.

Enfim, ao invés de pensar sobre a Verdade em termos metafisicos e de absoluto, sugere que se

\footnotetext{
RORTY, R. A contingência da linguagem. In: Contingência, ironia e solidariedade. São Paulo: Martins Fontes, 2007, p. 55

RORTY, R. A contingência da linguagem. In: Contingência, ironia e solidariedade. São Paulo: Martins Fontes, 2007 , p. 37.

BAUMAN, Z., O mal-estar na pós-modernidade. Rio de Janeiro: Zahar, 1997. p. 142.

RORTY, R. A contingência da linguagem. In: Contingência, ironia e solidariedade. São Paulo: Martins Fontes, 2007, p. 53.
} 
analise os usos para a palavra verdade e assume o termo verdade no sentido de direcionamento, recomendação e indicação de uma rota a ser seguida, mas que pode mudar caso seja necessário. Ademais, diz que o termo verdade seria um termo geral de aprovação, um meio de recomendar aquele ponto de vista. ${ }^{39}$

Cabe ressaltar que uma teoria ironista é quase uma não-teoria. De fato, isso porque, conforme Bauman aponta, existe um problema quando se fala em verdade. Isso porque, ao se estabelecer regras e teorias sobre o tema, será composta uma trilha para poucos escolhidos que teriam o papel de decidir o que é verdade e que, aos mortais comuns, resta a aceitação das palavras dos seus profetas, retroalimentando a concepção do autor de que quem detém o estandarte da verdade, detém o poder. Assim, seria novamente a busca pela única teoria acerca do assunto que permitiria o alcance ou manutenção de alguma forma de poder e sustentaria questões como pós-verdade e fake news.

No cerne da luta estariam, justamente, aqueles que acreditam que podem alcançar a Verdade e utilizam-se dessa crença para a manipulação de expectativas e informações. E, com isso, definindo que sua posição não vem de um contexto ou tradição e, sim, que representam um ponto de vista transcendental e absoluto.

Por isso, desenvolver um pensamento diverso sobre a verdade através dessa não-teoria delineada por Richard Rorty será um pensamento pautado muito mais pela desconstrução da metafísica do que pela enumeração de métodos. o que ele busca fazer é não um lamento sobre a perda de objetividade; mas, sim, enxergar a rejeição da metafísica como uma condição de possibilidade para a aceitação de múltiplas possibilidades de apreensão de conhecimento.

Destarte, as teorias ou a sua não-teoria encaminha-se para a intersubjetividade e definido o ceticismo como uma posição de segunda ordem sobre a impossibilidade de alcançar a verdade. Haja vista que, para o ceticismo arquimediano não existe qualquer possibilidade de conhecimento porque só haveria conhecimento puro quando se alcançasse o ponto arquimediano, o metanivel, entende-se que Rorty, longe de ser cético, explica que "só podemos produzir uma concepção melhor de racionalidade ou moralidade se operarmos dentro de nossa própria tradição".40 Ou seja, para o autor, devemos parar de preocuparmonos com o ponto arquimediano como base para avaliação de conhecimento e entender que há intersubjetividade na questão da verdade.

Diante de tal premissa, percebe-se que Richard Rorty realiza uma defesa do que é definido como contextualismo que "é a tese que defende que algo (como o conhecimento, os significados, as normas morais ou as práticas culturais) depende de um determinado contexto social, histórico e cultural ou de um esquema conceptual".41 Já Engelke adverte que é possivel definir o contextualismo como relativismo em sentido fraco, porque defende que se não há um fundamento absoluto para o sistema de crenças, nem um critério último que garanta o estatuto de verdade a alguma crença específica, "então a verdade será sempre relativa, contingente, produto de configurações particulares de tempo, lugar e acaso".42 Mas, mesmo assim, relativismo em sentido fraco é algo muito diverso do ceticismo.

Para Rorty, será o contextualismo somado à temporalidade que deve ser observado no processo de busca por conhecimento. Sendo em parte herdeiro de uma tradição hermenêutica segundo as linhas de Heidegger, ele acredita que a compreensão somente torna-se possivel por conta da existência de uma presença compartilhada em termos de tradições e linguagem e, por isso, não há como ser dotado de um ponto arquimediano de avaliação ou questionamento.

\footnotetext{
39 RORTY, R., Objetivismo, relativismo e verdade. Rio de Janeiro; Relume Dumará, 1997, p. 40.

40 RORTY, R. Objetivismo, relativismo e verdade. Rio de Janeiro: Relume Dumará, 1997, p. 269.

41 SAMPAIO, R. O Problema do Relativismo em Heidegger e Gadamer. In: Investigaciones Fenomenológicas, n.6, 2008, p. 283-298. Disponivel em: https://doi.org/10.5944/rif.6.2008. Acesso em: 27 jan. 2020, p. 287

42 ENGELKE, A. C., M. T. Relativismo e Ceticismo na obra de Richard Rorty. In: Desigualdade \& Diversidade - Revista de Ciências Sociais da PUC-Rio, n.12 e 13, Edição Dupla, jan. /dez. 2013, p. 171-189. Disponivel em: http://desigualdadediversidade.soc.puc-rio.br/cgi/cgilua. exe/sys/start.htm. Acesso em: 27 jan. 2020, p. 175
} 
A defesa da presença feita por Rorty está na base de sua argumentação de um ponto de vista intersubjetivo para a questão da verdade. Quando desconstrói a metafísica e questiona a objetividade, ele age "por dentro" de uma tradição, de uma presença que avalia crenças metafísicas como negativas e prejudiciais para o desenvolvimento da filosofia. Não está realizando uma crítica sustentada em uma posição cética arquimeadiana e, sim, em uma posição contextualista.

Isso não deve ser confundido com o ceticismo; trata-se, portanto, de ideias distintas, posto que o contextualismo defendido por Rorty debate a intersubjetividade e será por essa linha que ele desenvolve o que seria a critica ironista. Para Rorty, ao contrário do que Dworkin acredita, um ironista é alguém bem distante de um cético, desde que para o autor, um ironista liberal seria algo bastante diferente, seria quem encara corajosamente a contingência que começa em suas próprias crenças e desejos, até mesmo os mais significativos, e sabe que até sua identidade está relacionada ao tempo e ao acaso.

É por essa via que fica evidente a diferença entre a tese de Richard Rorty, amparada pelo contextualismo e pelo falibilismo, do ceticismo e da subjetividade que formam o palco para o surgimento da pós-verdade e das fake news. Cabe esclarecer que o cético é aquele que gostaria de uma garantia contra toda e qualquer possivel objeção futura.

Rorty explica que o ceticismo é em si, um pranto, uma agonia, um enorme lamento porque não consegue "achar a verdade". Céticos são irmãos dos fundacionistas, o ceticismo pranteia e lamenta, discorrendo sobre a impossibilidade do conhecimento verdadeiro; enfim, eles partem do mesmo ponto dos essencialistas metafísicos, ou seja, o ceticismo é a outra face do fundacionismo e, com sua intransigência, tece o pano de fundo sobre o qual se erigem a pós-verdade e as fake news.

Será diante dessa posição contextualista que se passa para um segundo conceito relevante da teoria deflacionista sobre a verdade de Richard Rorty e esse conceito contesta a necessidade metafísica de encontrar essências atemporais e eternas. Para o autor, a contingência é algo a ser mantido em consideração permanente, o que implica em, diante da questão do conhecimento ser proposicional, saber que as coisas ganharão descrições positivas, negativas e diversas ao longo da história, ao longo da mudança de jogos de linguagem e, por isso, há que se abandonar essa busca por essências.

É nesse sentido que se pode afirmar que ele defende o que se chama de falibilismo, ou seja, acredita que não manter um ponto de vista como dogmático favorece a revisão das crenças caso haja circunstâncias que motivem essa revisão. É um termo criado por Peirce, um dos principais pensadores do pragmatismo filosófico, para indicar a atitude do pesquisador que julga possivel o erro a cada instante da sua pesquisa e, portanto, procura melhorar os seus instrumentos de investigação e de verificação. ${ }^{43}$

Peirce, ao discorrer sobre a ciência e métodos científicos, reconhecia, como garantia única da validade da ciência, justamente a sua auto corrigibilidade e a desistência de "qualquer pretensão à garantia absoluta". Engelke relembra que Rorty disserta com aprovação sobre o elogio de Joseph Schumpeter ao falibilismo quando este disse que reconhecer a validade relativa das próprias convicções, mas, ainda assim, defendêlas resolutamente é o que distingue o homem civilizado do bárbaro. ${ }^{44}$

Perceba-se, por conseguinte, que não é por enfrentar a possibilidade do tema que uma crença será menos digna de ser defendida. Mesmo diante da possibilidade do erro e da contingência, certas convicções serão defendidas e avaliadas em bases contextuais e falibilistas. Consequentemente, umas das principais ideias de Rorty é a rejeição da Verdade metafísica em direção à aceitação de verdades minúsculas, intersubjetivas e plurais.

Por isso que Bauman apresenta a obra de Rorty como uma vigorosa afirmação, no sentido de 
que essa descrição da história como a "marcha irrefreável do erro para a verdade e da insensatez e superstição para o império da razão" 45 pode e deve ser revista a partir da noção de continuidade na visualização das contingências. Isso permite que, ao invés de tomar a história como um caminho paulatino em direção ao esclarecimento, as contingências e multiplicidades contextuais e sucessivas sejam sobrelevadas, possibilitando que a questão sobre a verdade não seja mais tratada em termos metafísicos.

Falar sobre isso implica em negar o ceticismo que se encontra na base da pós-verdade e das fake news, que se nutrem da subjetividade e não da intersubjetividade. Perceba-se a possibilidade de entender o ceticismo como apenas outro lado do chamado essencialismo metafisico, porque ambos partem da mesma premissa e defendem, por caminhos aparentemente diferentes, os mesmos posicionamentos.

Por isso, é possivel defender que, tanto a pósverdade como as fake news, não são resultados da pós-modernidade como paradigma filosófico, não são resultados da desconstrução da metafísica: são, de fato, restos esquecidos da continuação da tradição metafísica ainda por serem destruídos no caminho da desconstrução.

\section{O Falibilismo, o Contextualismo e a Autorreflexividade Como Anteparos da Intersubjetividade}

A teoria desenvolvida por Rorty afasta-se completamente tanto da subjetividade como da objetividade e acredita na possibilidade de "continuar a tecer uma narrativa edificante sem pegar em armas metafísicas". ${ }^{46}$ Essa sua observação é salutar no sentido de mostrar que existe esperança além da metafísica. Ou seja, não é apenas sobre os ombros de teorias metafísicas que reside a esperança da possibilidade de convivência humana pacífica, incluindo uma troca informacional proveitosa que aprenda com erros e desacertos do passado, mantendo em vista a possibilidade de mudanças no futuro.

O que deve ser alcançado diante das presentes observações sobre o contextualismo e o falibilismo é a visão de que ambos abrem espaço para a autorreflexividade, contrária ao cogito digital que prega a indubitabilidade do eu, frente a dúvida sobre o todo. Justamente por estar ciente de que suas crenças não representam qualquer essência atemporal e absoluta, abre-se espaço para a autorreflexividade.

Em primeiro lugar, há que se tratar desse fenômeno sobre o indivíduo e, nesse ponto, é esclarecedor buscar algumas raizes hermenêuticas para a autorreflexividade e a intersubjetividade. Nesse sentido, Gadamer recorda que Dilthey desenvolveu a teoria sobre círculo de compreensão e aprimora o conceito de autorreflexividade justamente através do res cogitans de Descartes.

Como explica Gadamer, Dilthey parte da vida e do autoconhecimento, pois o conceito de "interiorização (Inmesein), que caracteriza a vivência, contém uma espécie de retorno da vida sobre si mesma". ${ }^{47}$ Esse é, inclusive, um dos pontos de distinção entre Dilthey e Husserl, não obstante ambos terem se debruçado sobre essa questão, Husserl anda pelo caminho da empatia e Dilthey, pelo da psicologia.

Gadamer explica que a questão da interiorização diz respeito "às dificuldades que nos coloca o problema da intersubjetividade e a compreensão do eu estranho".48 Como reconhecer o Outro? A resposta vem de Heidegger que desenvolve a hermenêutica como ontologia. Destarte, o reconhecimento é da própria essência da vida e, por isso, o filósofo tem por meta conceber a partir da vida e define que é a própria facticidade da existência que deve ser o ponto de partida. É uma mudança significativa: ao invés de se partir de abstrações, alçar o cotidiano ao ápice.

É assim que Heidegger combate justamente a subjetividade transcendental que, originada em Descartes, encontra ainda apoio na filosofia

\footnotetext{
BAUMAN, Z., O mal-estar na pós-modernidade. Rio de Janeiro: Zahar, 1997. p. 89

RORTY, R., Objetivismo, relativismo e verdade. Rio de Janeiro: Relume Dumará, 1997, p. 282.

GADAMER, H. G. Verdade e Método. Rio de Janeiro: Vozes, 1999, p. 359.

48 GADAMER, H. G. Verdade e Método. Rio de Janeiro: Vozes, 1999, p. 379
} 
de Husserl sendo replicada em suas cogitatios. Recordando brevemente a ligação entre Husserl e Heidegger, é interessante observar que Husserl parte da indubitabilidade do conhecimento, pois para ele a vivência é intelectiva e toda vivência em geral pode se fazer objeto de um puro ver. De acordo com Husserl, há uma esfera de dados absolutos que fundamenta uma teoria de conhecimento. ${ }^{49}$

A intencionalidade de Husserl reescreve-se em Heidegger, que entende o que era chamado de natural, era histórico e espaço-temporal, definindo que é o homem que jogado no mundo, usa as coisas para a sua existência. O homem é ser-nomundo, e essa concepção o afasta do idealismo, já que para Heidegger, o "eu" é sempre ôntico e o sentido é fixado a partir do sujeito.

Contudo, ultrapassa-se a subjetividade no momento em que é o mundo, ao qual o sujeito está aberto, que lhe permite a compreensão, que a possibilita. O simples fato de "ser-no-mundo" impede o solipsismo desse eu fundamental do idealismo.

Ao mesmo tempo, elevando a questão do ser e da verdade à temporalidade. Heidegger rejeita o absolutismo do essencialismo e explica que ser é tempo, derrubando a subjetividade cartesiana. Mas, a questão precisa seguir adiante. E faz isso quando ele percebe que desde que o homem, consciente da finitude do seu ser, consciente da sua não eternidade, vive a experiência, que é experiência da limitação humana.

Conforme Gadamer chama atenção, será "experimentado, no autêntico sentido da palavra, aquele que é consciente desta limitação, aquele que sabe que não é senhor do tempo nem do futuro".50 Para ele, a verdadeira experiência é a experiência da historicidade.

Gadamer explica ainda que a experiência hermenêutica tem a ver com tradição e é ela que deve chegar à experiência, que é linguagem, fala por si mesma, como faz um tu. Recordando Heidegger, se o reconhecimento faz parte da ontologia, é possivel falar que há uma experiência do tu, que é também um fenômeno moral que se debruça para a compreensão do outro e essa experiência do tu modifica a estrutura da própria experiência.

Segundo Gadamer, há duas maneiras dessa experiência do tu desenvolver-se: a primeira é usar o outro como um meio para nossos fins; a segunda é reconhecer o tu como pessoa e formar uma relação reflexiva e, assim:

\begin{abstract}
o tu perde a imediatez com que orienta suas pretensões a respeito de alguém, porque ao fim e ao cabo, todos estão lutando pelo reconhecimento reciproco. A experiência do tu é enriquecedora e não busca ver no outro um meio, um "instrumento completamente dominável e manejável. ${ }^{1}$
\end{abstract}

É a diferença também observada por Oitaven sobre a necessidade de dar abertura ao Outro único, inclusive respeitando concepções alheias e contrapostas, devendo ser rejeitada uma "postura de arrogância, desprovida de abertura, humildade e resiliência quanto aos próprios erros".52 Em resumo, o que ele observa é que não é recomendável se manter uma postura de desrespeito perante um "outro Outro", perante aquele Outro que não compartilha as mesmas posições morais, por exemplo. Por isso que, para o autor, ser responsável é estar aberto e é preciso se aproximar do outro pensando em como acolher sua alteridade, fazendo um compromisso prévio com a intersubjetividade.

O pensamento de Oitaven encontra-se com o que é dito por Gadamer, que preconiza a abertura ao Outro e não a apropriação e redução deste para um outro Eu, porque seria importante "experimentar o tu realmente como um tu, isto é, não passar por alto sua pretensão e deixar-se falar algo por ele. A isso pertence a abertura".53 E isso é tão significativo que Gadamer acredita que, sem ela, não existe vínculo humano, porque "pertencer-se uns aos outros quer dizer sempre e ao mesmo tempo poder-ouvir-se-uns-aos-outros".

\footnotetext{
HUSSERL, E. A ideia da fenomenologia. Lisboa: Edições 70, 1992, p. 54

GADAMER, H. G. Verdade e Método. Rio de Janeiro: Vozes, 1999, p. 527

GADAMER, H. G. Verdade e Método. Rio de Janeiro: Vozes, 1999, p. 528-530

OITAVEN, D., P. M. A contradição performativa na luta estratégica dos movimentos sociais por reconhecimento: entre conflitos Honnethianos e consensos Habermasianos. Tese (Doutorado em Ciências Sociais) - Programa de Pós-Graduação em Ciências Sociais, Universidade Federal da Bahia. Salvador, BA, 2014. p. 17.

53 GADAMER, H. G. Verdade e Método. Rio de Janeiro: Vozes, 1999, p. 532
} 
E nada tem a ver com submissão, com escuta passiva, porque "escutar o outro" não significa, simplesmente, realizar às cegas o que o outro quer. Ao que é assim, chama-se submisso.

Gadamer explica que se abrir para a autorreflexividade não significa se apropriar do Outro com vistas a reduzi-lo a um outro Eu. O que deve ser feito é "deixar valer em mim algo contra mim, ainda que não haja nenhum outro que o vá fazer valer contra mim".54

Essas importantes considerações da hermenêutica são replicadas nas teses de Richard Rorty, que preconiza a relevância da ajuda ao próximo como meio de construção de uma sociedade viável, que busque sair da contemplação da objetividade e parta para a solidariedade, respeitando-se as diversas identidades narrativas de cada ser humano.

Diante do falibilismo e contextualismo das suas teses, percebe-se que se deve duvidar, principalmente, do eu e de suas crenças pessoais. Isso porque são contextuais e podem falhar. Elas não são absolutas, não representam a apreensão de qualquer essência atemporal e, por isso, abrem espaço para múltiplos debates e entendimentos, contrários ao cogito digital.

\section{Conclusão}

A partir da análise de conceitos metafísicos relacionados à forma de buscar conhecimento, foi possivel observar como as hipóteses sobre o conhecimento e a verdade eram construídas a partir de teorias substancialistas, reforçadas na modernidade. Elas buscavam um conhecimento objetivo e imparcial, narrado de forma neutra, com o combate de crenças particulares, visando alcançar uma espécie de excelência na neutralidade narrativa.

Dialeticamente, a pós-modernidade desponta a favor da liberdade e pode ser enxergada em suas duas faces. A primeira é resultado direto da rejeição da falsa segurança ofertada pela metafísica e, por isso, enfrenta os problemas ocasionados pela revolução digital e acesso à internet. Isso porque o que começou com a promessa de trocas informacionais amplas e genuinas, acabou por resultar em problemas como a pós-verdade e as fake news.

Percebeu-se, diante da exposição de argumentos formulados, que os dois problemas apontados, típicos da era digital, são questões que se alimentam da metafísica. Pois, o amplexo que nutre tanto a pós-verdade como as fake news é formado de defesa do ponto arquimediano, busca de uma informação neutra e "pura", sem qualquer ideologia, desconfiança de pontos de vistas contrários, negação do Outro e indubitabilidade das próprias crenças. Ele é, de fato, fruto da metafísica e uma negação da outra face da pósmodernidade, que é buscar a intersubjetividade através da rejeição da metafísica.

Diante das duas faces da pós-modernidade foram analisadas as teorias formuladas por Richard Rorty, autor do período pós-moderno criticado como defensor proeminente do ceticismo. Demonstrou-se que a sua ênfase no contextualismo, na contingência e na dúvida sobre nossas crenças não representam o pessimismo do ceticismo e sim uma posição adepta do não conformismo que defende ser preciso combater a placidez metafísica e suas falsas promessas de segurança, conduzindo ao entendimento da intersubjetividade na construção da verdade.

Se a pós-modernidade sobrelevou a liberdade como força máxima que afeta todos os aspectos da vida social, incluindo a troca informacional da era digital, certo é que esses pontos representam uma ampliação da subjetividade e são expurgos da metafísica. Para tanto, vale lembrar que esta é uma questão que nasce sob os mais valiosos auspícios e termina soterrada por acusações de falta de confiabilidade nas informações, impactos negativos nas democracias, fragmentação de conteúdos informacionais, pós-verdade e fake news.

Richard Rorty permite que se compreenda que o que se enfrenta hoje nas trocas comunicacionais são problemas da aceitação das contingências e uma busca pelo modo de como lidar com a insegurança. Essa face amarga 
da pós-modernidade representa justamente como lidar com a incertização do mundo, como lidar com os problemas da era digital tais como a pós-verdade e fake news. Será justamente a outra face da pós-modernidade que dará a resposta, pois diante da afirmação de que a segurança moderna é impossivel, cabe buscar outro caminho e esse caminho é oferecido pelas suas teorias que buscam caminhar dentre a incerteza e as contingências.

Nesse sentido, ao se analisar com profundidade a desconstrução da metafísica levada a cabo pelo autor, percebe-se que há um apelo à intersubjetividade e à autorreflexividade que o afastam do ceticismo e permitem desatar esse nó da pós-modernidade, ensinando a caminhar em um mundo de incertezas sem precisar de bases absolutas e atemporais. As caracteristicas contextualistas e falibilistas das suas teorias levam à autorreflexividade, questão relevante na era digital que se encontra assolada por problemas de confiabilidade com a informação.

De fato, acredita-se que será a autorreflexividade, e não o cogito digital, uma das chaves para a solução de questões como pós-verdade e fake news. Pois, ambas, alimentam-se de bases céticas e subjetivas, nutrindo um solipsismo contrário à intersubjetividade buscada por Richard Rorty.

Entende-se que, ao se perceber a possibilidade de erro e incorreção nas próprias crenças, haverá uma maior possibilidade de movimentos de autocorreção, checagem de dados, pesquisa e busca pela intersubjetividade, e não mais pela objetividade. Desistir da objetividade em favor da intersubjetividade significa entender como trabalhar com as contingências e seguir na desconstrução da metafísica diante da fragmentação inevitável na pós-modernidade.

\section{REFERÊNCIAS}

ABBAGnano, N. Dicionário de Filosofia. São Paulo: Martins Fontes, 2007

ADAMIC, E.; BAKSHY, S.; MESSING, L. Exposure to ideologically diverse news and opinion on Facebook. Science, [s. l.], v.348, n. 6239, p.1130-1132, 05 jun. 2015. Disponivel em: https://science.sciencemag.org/content/348/6239/1130. Acesso em: 27 jan. 2020. https:// doi.org/10.1126/science.aaa1160.
ALLCOTT, H.; GENTZKOW M. Social Media and Fake News in the 2016 election. Journal of Economic Perspectives, [s. l.], v. 31, n. 2, 2017, p. 211-236. Disponivel em https:// www.aeaweb.org/articles?id=10.1257/jep.31.2.211. Acesso em: 27 jan. 2020. https://doi.org/10.1257/jep.31.2.211.

BAUMAN, Z. O mal estar na pós-modernidade. Rio de Janeiro: Zahar, 1997.

CABETTE, A. F. O que é 'pós-verdade', a palavra do ano segundo a Universidade de Oxford. Nexo Jornal, [s. l.],16 de nov. 2016. Disponivel em: https:// www.nexojornal.com.br/expresso/2016/11/16/O-que-\%C3\%A9-\%E2\%80\% 98p\%C3\%B3s-verdade\%E2\%80\%99-a-palavra-do-ano-segundo-a-Universidade-de-Oxford. Acesso em: 12 mar. 2019

CASTILHO, C. Apertem os cintos: estamos entrando na era da pós-verdade. Observatório da imprensa, Is. l.], ed. 921, 28 set. 2016. Disponivel em: http://observatoriodaimprensa.com.br/imprensa-em-questao/ apertem-os-cintos-estamos-entrando-na-era-da-pos-verdade/. Acesso em: 27 jan. 2020.

DWORKIN, R. Objectivity and Truth: You'd better believe it. Philosophy \& Public Affairs, [s. l.], v. 25, n. 2, p.87-139, 1996. Disponivel em: https://www.jstor.org/ stable/2961920. Acesso em: 27 jan. 2020. https://doi. org/10.1111/j.1088-4963.1996.tb00036.x.

ENGELKE, A. C. M. T. Relativismo e Ceticismo na obra de Richard Rorty. Desigualdade \& Diversidade: Revista de Ciências Sociais da PUC-Rio, Rio de Janeiro, n. 1213. p. 171-189, jan./dez. 2013.. Disponivel em: http:// desigualdadediversidade.soc.puc-rio.br/cgi/cgilua. exe/sys/start.htm. Acesso em: 27 jan. 2020.

GADAMER, H.-G. Verdade e Método. Petrópolis: Editora Vozes, 1999

GOMES, W. A democracia digital e o problema da participação civil na decisão política. Revista Fronteiras: estudos midiáticos, [s. l.], v. 7. n. 3, p. 214-222, 2005. Disponivel em: http://revistas.unisinos.br/index.php/ fronteiras/index. Acesso em: 27 jan. 2020.

HEIDEGGER, M. Que é uma coisa? Lisboa: Edições 70, 1987.

HUSSERL, E. A ideia da fenomenologia. Lisboa: Ediçoes 70, 1992.

LYOTARD, J. F. A condição pós moderna. Rio de Janeiro: José Olympio, 2009.

OITAVEN, D., P. M. A contradição performativa na luta estratégica dos movimentos sociais por reconhecimento: entre conflitos Honnethianos e consensos Habermasianos. Tese (Doutorado em Ciências Sociais) - Programa de Pós-Graduação em Ciências Sociais, Universidade Federal da Bahia, Salvador, 2014.

POST-TRUTH". In: ON-LINE OXFORD DICTIONARY of English. Disponivel em: https://www.lexico.com/en/ definition/post-truth. Acesso em: 15 jul. 2019.

RORTY, R.; ENGEL, P. A. Para que serve a verdade? São Paulo: Unesp, 2007.

RORTY, R. Contingência, ironia e solidariedade. Cambridge: CUP, 1989. 
RORTY, R. Objetivismo, relativismo e verdade. Rio de Janeiro: Relume Dumará, 1997.

SAMPAIO, R. O Problema do Relativismo em Heidegger e Gadamer. Investigaciones Fenomenológicas, Is. l.], n. 6, p.283-298, 2008. Disponivel em: https://doi. org/10.5944/rif.6.2008. Acesso em: 27 jan. 2020.

SOLANO, E. Crise da democracia e extremismos de direita Friedrich-Ebert-Stiftung Brasil, [s. l.], n. 42, maio 2018. Disponivel em: http://library.fes.de/pdf-files/ bueros/brasilien/14508.pdf. Acesso em: 27 jan. 2020.

SOSA, E.; GRECO J. Compendio de epistemologia. São Paulo: Loyola, 2008.

SOUZA, Q. R.; QUANDT, C. O. Metodologia de Análise de Redes Sociais. In: DUARTE, F.; QUANDT, C. O.; SOUZA, Q. (org.). O Tempo das Redes. São Paulo: Perspectiva, 2008. p. 31-63.

TEUBNER, G. Direito, sistema e policontexturalidade. Piracicaba: Unimep, 2005.

ZAGZEBSKI, L. O que é conhecimento? São Paulo: Loyola, 2008.

\section{Alessandra Cavalcante Scherma Schurig}

Doutoranda em Filosofia do Direito pela Universidade Federal da Bahia.

\section{Endereço para correspondência}

Alessandra Cavalcante Scherma Schurig

Universidade Federal da Bahia

Av. Adhemar de Barros, s/no

Ondina 40170-110

Salvador, BA, Brasil 